\title{
DIMENSI KREATIVITAS SEMANTIK DALAM MEMBANGUN HARMONI MASYARAKAT
}

\author{
Albarra Sarbaini \\ Institut Agama Islam Negeri (IAIN) Metro \\ Jl. Ki Hajar Dewantara 15A Iring Mulyo Kota Metro \\ bars77.oke@gmail.com
}

\begin{abstract}
Abstack
The Dimension of Cretivity is a condition, or condition that is particularly characteristic and almost impossible to formulate completely, which the meaning is never fully understood, because each child has a level of creativity. Creativity involves the synthesis of all these functions. The section presented here is an integrative model that includes four basic functions: (a) national thinking, (b) emotional development or high-level feelings, (c) development of special talents in the mental and physical life, and $(d)$ the high degree of consciousness resulting in the use of imagination, fantasy, and break-through at the state of consciousness or unconsciousness. The semantics mean the theory of meaning or theory of meaning. Various kinds of complicated problems such as hostility, anger, resentment, humiliation, killing and even war in the world community generally and the people of Indonesia in particular occurs due to mistakes in saying words and sentences that berdampat on the meaning of words and sentences are diverse to cause conflict between hostility and hatred among ethnic communities and religion. It is a phrase Arabic proverb which means "The word can penetrate something that can not be penetrated by a needle", and also the expression "The survival of a person lies in how he keeps his mouth and his words".
\end{abstract}

Keywords: dimensie, creativiteit, integratief model, semantics

\begin{abstract}
Abstrak
Dimensi Kretivitas adalah suatu kondisi, sikap, atau keadaan yang khusus sifatnya dan hampir tak mungkin dirumuskan secara tuntas, yang mana pengertian itu tak pernah dipahami sepenuhnya, karena setiap anak memiliki kadar kreativitas. Kreativitas melibatkan sintesis dari semua fungsi ini. Bagian yang ditampilkan disini merupakan model integrative yang mencakup empat fungsi dasar, yaitu: (a) berfikir nasional, (b) perkembangan emosional atau perasaan tingkat tinggi, (c) perkembngan bakat khusus dalam kehidupan mental dan fisik, dan (d) tingkat tinggi kesadaran yang menghasilkan penggunaan imajinasi, fantasi, dan pendobrakan pada kondisi ambang kesadaran atau ketidaksadaran. Adapun semantik berarti teori makna atau teori arti. Berbagai macam komflik permasalahan seperti permusuhan, amarah, dendam, penghinaan, pembunuhan bahkan peperangan di masyarakat dunia umumnya dan masyarakat Indonesia khususnya terjadi diakibatkan kesalahan dalam mengucapkan kata dan kalimat yang berdampak pada pemaknaan kata dan kalimat yang beragam hingga menimbulkan konflik permusuhan dan kebencian antar masyarakat suku dan agama. Benarlah ungkapan peribahasa arab yang artinya "Perkataan itu dapat menembus sesuatu yang tidak mampu ditembus oleh jarum", dan juga ungkapan "Selamatnya hidup seseorang itu
\end{abstract}


terletak bagaimana dia menjaga lisan dan perkataannya”.

Kata Kunci: Dimensi Kretivitas, model integrative dan semantik

\section{Pendahuluan}

Bahasa adalah alat komunikasi yang dapat membentuk integritas kehidupan individualis kepada kehidupan sosial. ${ }^{1}$ Bahasa adalah sistem lambanglambang berupa bunyi yang digunakan oleh segolongan masyarakat tertentu untuk berkomunikasi dan berinteraksi. ${ }^{2}$ Menurut Tarigan, jika kita mengatakan bahwa bahasa adalah suatu sistem simbol-simbol, maka bahasa mengandung makna bahwa ucapan si pembicara dihubungankan secara simbolis dengan objek-objek ataupun kejadiankejadian dalam dunia praktis. ${ }^{3}$ Bahasa manusia berbeda dengan bahasa binatang. Menurut asep Ahmad Hidayat, bahasa manusia mempunyai ciri-ciri sebagai berikut: ${ }^{4}$

(1) Alat fisis yang digunakan bersifat tetap dan memiliki kriteria tertentu. (2) Organisme yang digunakan memiliki hubungan timbal balik. (3) Menggunakan kriteria pragmatik,

${ }^{1}$ Ali Ridha, Al Marja' fi al Lughah al 'Arabiyyah Nahwuha wa Sharfuha, (Beirut: Dar al Fikr), Cet. Ke-2, h.

${ }^{2}$ A. Akrom Malibary, Pedoman Pengajaran Bahasa Arab pada Perguruan Tinggi Islam Negeri (IAIN), (Jakarta: Depag RI, 1976), h. 19

${ }^{3}$ Asep Ahmad Hidayat, Filsafat Bahasa, (Bandung: PT Remavja Rosda Karya, 2006), h. 25 ${ }^{4}$ Ibid, h. 25 berkaitan dengan bunyi-bunyi segmental. (4) Mengandung kriteria semantis atau fungsi semantik tertentu. (5) Memiliki kriteria sintaksis, kata-kata yang digunakan untuk menjadi suatu kalimat harus disusun sesuai dengan pola kalimat yang telah disepakati. (6) Melibatkan unsur bunyi ataupun unsur audiovisual. (7) Memiliki kriteria kombinasi dan bersifat produktif. (8) Bersifat arbitrer, mana suka. (9) Memiliki ciri prevarikasi. (10) Terbatas dan relatif tetap. (11) mengandung kontiniuitas dan mengandung diskontiniuitas. (12) Bersifat hierarkis, yaitu pemakaian keberadaannya memiliki tataran yang berada dalam tata tingkat tertentu. (13) Bersifat sistemis dan simultan. (14) Saling melengkapi dan mengisi, baik secara paradigmatis maupun sintagmatis. (15) Informasi kebahasaan dapat disegmentasi, dihubungkan, disatukan dan diabadikan. (16) Transmisi budaya. (17) Bahasa itu dapat dipelajari. (18) Bahasa itu dalam pemakaian bersifat bidimensional.

Dilihat dari fungsi bahasa di, pemahaman terhadap bahasa itu sendiri perlu diperhatikan. Makna kata yang digunakan dalam proses komunikasi adalah hal yang penting untuk dikuasai, sehingga pemilihan kata yang tepat dapat mewujudkan fungsi penting dari bahasa. Secara praktis kajian 
bahasa terus berkembang sesuai dengan kebutuhan dan tuntutan hidup manusia, bahasa tidak lagi dikaji sebagai ilmu yang tersendiri, tetapi dikaji sebagai ilmu multidisipliner yang digabungkan dengan kajian ilmu lainnya, seperti sosiolinguistik, psikolinguistik, leksikografi, pengajaran bahasa (metode, evaluasi, analisis kesalahan dan komparasi bahasa), serta ilmu-ilmu lainnya. Namun jika ditinjau secara teoritis, bahasa mencakup kajian fonologi, sejarah bahasa, semantik dan gramatika (morfologi dan sintaksis). Jika fonologi berbicara tentang bunyi bahasa, gramatika berbicara tentang perubahan bentuk kata dan fungsi kata dalam kalimat, maka semantik berbicara tentang makna bahasa baik pemahaman tentang hakikat makna kata, makna kalimat, maupun makna dari proses komunikasi.

Menurut kambartel semantik adalah studi tentang makna, menurutnya semantik mengasumsikan bahwa bahasa terdiri dari struktur yang menampakan makna apabila dihubungkan dengan objek dalam pengalaman dunia manusia. Sedangkan verhaar mengatakan bahwa semantik berarti teori makna atau teori arti.Batasan yang hampir sama ditemukan pula didalam ensiklopedia britanika yang terjemahannya " Semantik adalah studi tentang hubungan antara suatu pembeda linguistik dengan hubungan proses mental atau simbol dalam proses dalam aktivitas bicara." Memang secara empiris sebelum seseorang berbicara dan ketika seseorang mendengar ujaran seseorang, terjadi proses mental pada diri keduanya. Proses mental itu berupa proses menyusun kode semantis, kode gramatikal, dan kode fonologis pada pihak pembicara, dan proses memecahkan kode fonologis, gramatikal dan kode semantis pada pihak pendengar. Dengan kata lain baik pada pembicara ataupun pihak pendengar terjadi proses pemaknaan. ${ }^{5}$

Jika bahasa sebagai alat komunikasi menjadikan seseorang mengetahui kebutuhan, kepentingan, maksud dan tujuan seseorang, atau sebagai alat untuk menyatakan perasaan, harapan, keinginan, dan fikiran, juga mampu menyatukan kelompok masyarakat yang mempunyai perbedaan ras, agama dan perbedaan sosial ekonomi lainnya, maka makna yang terkandung di dalam suatu bahasa harus benar dan sesuai dengan aturan-aturan bahasa yang telah disepakati. Pemahaman tentang makna ini harus dikuasai terutama bagi komunikan, agar maksud dan tujuan dari komunikator dapat difahami dengan baik. Komunikasi yang baik akan menciptakan hubungan interaksi yang baik pula, dan pada akhirnya keharmonisan masyarakat dapat terwujud. Namun sebaliknya, jika komunikan tidak memahami makna bahasa komunikator

${ }^{5}$ Mansoer Pateda, Semantik Leksikal, (Jakarta: Rineka Cipta, 2010), h. 7 
maka hubungan interaksi tidak akan berlangsung baik dan keharmonisan masyarakat pun tidak akan terwujud.

Berbagai macam komplik permasalahan seperti permusuhan, amarah, dendam, penghinaan, pembunuhan bahkan peperangan di masyarakat dunia umumnya dan masyarakat indonesia khususnya terjadi diakibatkan kesalahan dalam mengucapkan kata dan kalimat yang berdampat pada pemaknaan kata dan kalimat yang beragam hingga menimbulkan komflik permusuhan dan kebencian antar masyarakat suku dan agama, sebagai contoh permasalahan yang terus bergulir sampai hari adalah, ungkapan kalimat Gubernur DKI Jakarta Basuki Cahaya Purnama tentang sosok pemimpin yang di kaitkan dengan surat maidah ayat 51. Ungkapan kalimat yang memicu kemarahan sebagian besar umat muslim Indonesia bahkan dunia.

Benarlah ungkapan peribahasa arab yang artinya "Perkataan itu dapat menembus sesuatu yang tidak mampu ditembus oleh jarum", dan juga ungkapan "Selamatnya hidup seseorang itu terletak bagaimana dia menjaga lisan dan perkataannya”.

\section{Pembahasan}

\section{Dimensi kreativitas}

Dimensi Kretivitas adalah suatu kondisi, sikap, atau keadaan yang khusus sifatnya dan hampir tak mungkin dirumuskan secara tuntas, yang mana pengertian itu tak pernah pernah di pahami sepenuhnya, karena setiap anak memiliki kadar kreativitas tertentu, tetapi kadar tersebut berkurang atau menghilang pada waktu ia menjadi dewasa. Sementara beberapa orang menganggap bahwa kreativitas itu sama dengan keberbakatan, sedangkan sementara pendapat mengkaitkannya dengan perkembangan penalaran dan perkembangan afektif.

Konsep terbaru dari kreativitas yang menonjol dalam filsafat abad ke-20 didasarkan atas fungsi dasar berfikir, merasa, penginderaan cipta talen, dan intuisi. Kreativitas melibatkan sintesis dari semua fungsi ini. Bagian yang ditampilkan disini merupakan model integrative yang mencakup empat fungsi dasar, yaitu: (a) berfikir nasional, (b) perkembangan emosionalatau perasaan tingkat tinggi, (c) perkembngan bakat khusus dalam kehidupan mental dan fisik, dan (d) tingkat tinggi kesadaran yang menghasilkan penggunaan imajinasi, fantasi, dan pendobrakan pada kondisi ambang kesadaran atau ketidaksadaran. ${ }^{6}$ Jadi, kreativitas selalu mencakup interpretasi keseluruhan kehidupan berfikir, merasa, mengindera, dan intuisi, yang terjadi secara menyatu dan menerobos. Dengan bergeraknya satu fungsi atau sebagian fungsi

${ }^{6}$. Conny R. Semiawan, Made Putrawan dan Setiawan, Dimensi Kreatif dalam Filsafat ilmu, (Bandung: Remaja Rosdakarya Offset, 1991),, h 61. 
dari keseluruhan fungsi saja, kreativitas itu belum terjadi sepenuhnya.

Proses kreativitas yang mempunyai empat tahap seperti yang dilukiskan oleh Graham Wallas memiliki tiga tingkat sesuai sesuai dengan pendapat Gowan dan Treffinger, yang mana ketiga tingkat tersebut adalah tingkat kreativitas, tingkat psikodelik, dan tingkat iluminatif. $^{7}$

a. Tingkat I: Yang disebut tingkat kreativitas, ditandai oleh ciri-ciri timbulnya pemikiran yang abru secara intuitif, atau penemuan fikiran baru yang hidup di masyarakat itu. Dari segi efektif kehidupan tingkat ini ditandai oleh keterbukaan dan toleransi terhadap keraguan tentang sesuatu. Kehidupan perasaan ditandai oleh kepercayaan diri sendiri dalam menghadapi tantangan.

b. Tingkat II: Yang disebut tingkat psikodelik (perluasan fikiran dan perasaan), ditandai oleh pengembangan kesadaran untuk menjangkau pada pandangan di luar pandangan ataupun kebiasaan kita sendiri dan penerimaan ide serta respon yang berbeda untuk diterima dan dihormati sebagai sesuatu yang original.

c. Tingkat III: Yaitu tingkat imajinatif. Pada tingkat ini sudah ada perkembangan produk atau hasil (product development), ciri utama dari product development ini dalah sudah teresapinya empat tahap perkembangan kreatif dan telah pula ada penerimaan dari penemuan tersebut dalam kelompok tertentu.

${ }^{7}$. Conny R. Semiawan, dkk, ibid, h 68.
Pada tingkat ini sudah dapat dihasilkan produk, yaitu sutu bentuk baru dari suatu pola, model, struktur, ataupun konsep yang sebelumnya belum atau tidak dikenal oleh kelompok manusia tertentu.

\section{Semantik}

Menurut Kambartel semantik adalah studi tentang makna, menurutnya semantik mengasumsikan bahwa bahasa terdiri dari struktur yang menampakan makna apabila dihubungkan dengan objek dalam pengalaman dunia manusia. Sedangkan verhaar mengatakan bahwa semantik berarti teori makna atau teori arti. Batasan yang hampir sama ditemukan pula didalam ensiklopedia britanika yang terjemahannya “ Semantik adalah studi tentang hubungan antara suatu pembeda linguistik dengan hubungan proses mental atau simbol dalam proses dalam aktivitas bicara." Memang secara empiris sebelum seseorang berbicara dan ketika seseorang mendengar ujaran seseorang, terjadi proses mental pada diri keduanya. Proses mental itu berupa proses menyusun kode semantis, kode gramatikal, dan kode fonologis pada pihak pembicara, dan proses memecahkan kode fonologis, gramatikal dan kode semantis pada pihak pendengar. Dengan kata lain baik pada pembicara ataupun pihak pendengar terjadi proses pemaknaan. ${ }^{8}$

Ada tiga cara yang dipakai oleh para filusuf dan linguis dalam usaha menjelaskan makna kata dalam bahasa manusia:

a. Makna Kata (leksikon)
Makna kata atau makna leksikal adalah makna unsur- unsur bahasa sebagai lambang, peristiwa dan lain lain. Makna leksikal ini dimiliki unsur- unsur bahasa secara (Jakarta: Rineka Cipta, 2010), h. 7 
tersendiri, lepas dari konteks. Misalnya kata culture ( bahasa inggris) budaya didalam kamus. Kata- kata tersebut tersebut memiliki makna dan dapat dibaca dalam kamus. Makna yang demikian disebut makna kamus, selain makna leksikal. Adapula yang mengatakan bahwa makna leksikal adalah makna katakata sewaktu berdiri sendiri, baik dalam waktu turunan maupun dalam bentuk dasar. ${ }^{9}$

b. Makna Kalimat (gramatikal)

Menurut Kamus Besar Bahasa Indonesia (2008: 461), gramatikal diartikan sesuai dengan tata bahasa. Dimana makna katanya mengalami proses afiksasi, reduplikasi, komposisi, atau kalimatisasi. Makna dari gramatikal sendiri adalah kata yang berubah-ubah sesuai dengan konteks (berkenaan dengan situasinya, yakni tempat, waktu, dan lingkungan penggunaan bahasa) pemakainya. maka kalimat gramatikal adalah kalimat yang makna katanya berubah-ubah karena mengalami proses pengimbuhan, pengulangan ataupun pemajemukan yang disesuaikan menurut tata bahasa serta terikat dengan konteks pemakainya.

Adalah makna yang menyangkut hubungan intra bahasa, atau makna yang muncul sebagai akibat fungsinya sebuah

9 T.Fatimah Djajasudarma, Semantik2, (Bandung: Refika Aditama, 2009), h.12 kata didalam kalimat. ${ }^{10}$ Didalam semantik makna gramatikal dibedakan dari makna leksikal.makna leksikal dapat berubah menjadi makna gramatikal, contohnya:

a. Polisi memasang belenggu pada kaki dan tangan pencuri yang baru tertangkap itu.

b. Mereka terlepas dari belenggu penjajahan.

Perubahan makna leksikal ke makna kalimat atau gramatikal dapat kita perhatikan ekspresi berikut:

a. Hei, mana matamu!

b. Anak itu ingin telur mata sapi.

c. Makna dari proses komunikasi

Adalah makna yang disimpulkan dari hasil komunikasi. Proses komunikasi terbagi menjadi 2 (dua) tahap, yaitu proses komunikasi secara primer dan proses komunikasi secara sekunder.

a. Proses Komunikasi Secara Primer

Pengertian proses komunikasi secara primer adalah proses penyampaian pikiran dan perasaan seseorang kepada orang lain dengan menggunakan lambang (simbol) sebagai media. Lambang yang dipergunakan sebagai media primer dalam proses komunikasi ialah bahasa, gambar, isyarat, warna dan lain sebagainya yang secara langsung mampu menerjemahkan pikiran dan perasaan komunikator kepada komunikan.Bahasa merupakan yang paling banyak digunakan untuk menerjemahkan pikiran seseoarang

\footnotetext{
${ }^{10}$ T.Fatimah Djajasudarma,Semantik2, h. 16
} 
kepada orang lain. Kial, isyarat, gambar, warna dan lain sebagainya, hanya dapat mengomunikasikan hal-hal tertentu saja (sangat terbatas).

b. Proses Komunikasi Secara Sekunder

Pengertian Proses Komunikasi secara sekunder adalah proses penyampaian pesan oleh seseorang kepada orang lain dengan menggunakan alat atau sarana sebagai media kedua setelah memakai lambang sebagai media pertama.Seorang komunikator menggunakan media kedua dalam melancarkan komunikasinya karena sebagai sasarannya berada di tempat yang relatif juga atau jumlahnya banyak. Surat, telepon, majalah, surat kabar, radio, televisi dan banyak lagi adalah media kedua yang sering dipergunakan dalam komunikasi.

Pada umumnya memang bahasa yang paling banyak digunakan dalam komunikasi karena bahasa sebagai lambang mampu mentransmisikan pikiran, pendapat, ide dan lain sebagainya, baik mengenai hal yang abstrak maupun yang konkret; tidak saja mengenai hal atau peristiwa yang terjadi pada saat sekarang, akan tetapi juga pada waktu yang lalu atau masa yang akan datang. Kebanyakan media merupakan alat atau sarana yang diciptakan untuk meneruskan pesan komunikasi dengan bahasa. Telepon, surat, radio merupakan media untuk menyambung atau menyebarkan pesan yang menggunakan bahasa.

Berbagai macam komplik permasalahan seperti permusuhan, amarah, dendam, penghinaan, pembunuhan bahkan peperangan di masyarakat dunia umumnya dan masyarakat indonesia khususnya terjadi diakibatkan kesalahan dalam mengucapkan kata dan kalimat yang berdampat pada pemaknaan kata dan kalimat yang beragam hingga menimbulkan komflik permusuhan dan kebencian antar masyarakat suku dan agama, sebagai contoh permasalahan yang terus bergulir sampai hari adalah, ungkapan kalimat Gubernur DKI Jakarta Basuki Cahaya Purnama tentang sosok pemimpin yang di kaitkan dengan surat maidah ayat 51 . Ungkapan kalimat yang memicu kemarahan sebagian besar umat muslim Indonesia bahkan dunia.

\section{Kesimpulan}

Bahasa sebagai alat komunikasi yag memiliki makna ( Sematik) menjadikan seseorang mengetahui kebutuhan, kepentingan, maksud dan tujuan seseorang. Bahasa adalah alat seseorang untuk menyatakan perasaan, harapan, keinginan, dan fikiran. Bahasa mampu mewujudkan ide/gagasan yang belum mempunyai bentuk dalam fikiran manusia. Dengan adanaya bahasa, seseorang dapat meyakinkan orang lain atau mempengaruhi sekelompok 
masyarakat. Bahasa juga mampu menyatukan kelompok masyarakat yang mempunyai perbedaan ras, agama dan perbedaan sosial ekonomi lainnya. Dalam cakupan yang lebih luas, bahasa menjadi penghubung antara suatu bangsa dengan bangsa lain sehingga dianggap salah satu faktor penting dalam menjaga hubungan dan perdamaian dunia. Jika penggunaan bahasa disalahartikan, maka bahasa mampu menjadi senjata yang dapat merusak hubungan antar masyarakat.

Pemahaman tentang makna ini harus dikuasai terutama bagi komunikan, agar maksud dan tujuan dari komunikator dapat difahami dengan baik. Komunikasi yang baik akan menciptakan hubungan interaksi yang baik pula, dan pada akhirnya keharmonisan masyarakat dapat terwujud. Namun sebaliknya, jika komunikan tidak memahami makna bahasa komunikator maka hubungan interaksi tidak akan berlangsung baik dan keharmonisan masyarakat pun tidak akan terwujud.

Benarlah ungkapan peribahasa arab yang artinya "Perkataan itu dapat menembus sesuatu yang tidak mampu ditembus oleh jarum”, dan juga ungkapan "Selamatnya hidup seseorang itu terletak bagaimana dia menjaga lisan dan perkataannya”.

\section{Daftar Pustaka}

Arikunto,Suharsimi.Prosedur Penelitian Suatu Pendekatan Praktek. Jakarta: PT. Rineka Cipta. 2002

Arsyad,Azhar.Madkhal ila Thuruq Ta'lim al Lughah al 'Ajnabiyyah. Mesir: Maktabah An Nahdhah Al Mishriyyah. 1999

Djajasudarma, T. Fatimah. Semantik2. Bandung: Refika Aditama. 2009

Hidayat, Asep Ahmad. Filsafat Bahasa. Bandung: PT. Remaja Rosda Karya. 2006

Malibary,A. Akrom.Pedoman Pengajaran Nahasa Arab pada Perguruan Tinggi Islam Negeri (IAIN). Jakarta: Depag RI. 1976

Moleong,Lexy.Metodologi Penelitian Kualitatif. Bandung: PT. Remaja Rosdakarya. 2004

M. Pidarta.Studi tentang Landasan Kependidikan; Jurnal, Filsafat, Teori dan Praktik Kependidikan. Jakarta. 1999

Mukhtar.Bimbingan Skripsi, Tesis dan Karya Ilmiah. Jakarta: Gaung Persada Press. 2007

Muzakki, Akhmad.Pengantar Teori Sastra Arab. Malang: UIN Maliki Press. 2011

Pateda,Mansoer.Semantik Leksikal. Jakarta: Rineka Cipta. 2010

Rangkuti, Bahrum dan Kafrawi.Pedoman Pengajaran Bahasa Arab. Jakarta: Proyek Pengembangan Sistim Pendidikan Agama Departemen Agama RI1974

Ridha,Ali.Al Marja' $f i$ al Lughah al 'Arabiyyah Nahwuha wa Sharfuha. Beirut: Dar al Fikr 
Rosyidi, Abd Wahab dan Mamlu'atul Ni'mah. Memahami Konsep Dasar Pembelajaran Bahasa Arab. Malang: UIN Maliki Press. 2012

Semiawan,Conny R., Made Putrawan dan Setiawan. Dimensi Kreatif dalam Filsafat ilmu. Bandung: Remaja Rosdakarya Offset. 1991

Suryabrata,Sumadi. Metodologi Penelitian. Jakarta: Rajawali Pers. 1988

Surachmad,Winarno.Pengantar Penelitian Ilmiah: Dasar Metode dan Teknik. Bandung, 1990

Wahab, Abdul. Isu Linguistik Pengantar Bahasa dan Sastra. Surabaya: Airlangga. 1998

Zulhannan. Paradigma Baru Pembelajaran Bahasa Arab. Bandar Lampung: An Nur Press. 2004 